\title{
Quality of life and survival of septuagenarians and octogenarians after repair of descending and thoracoabdominal aortic aneurysms
}

\author{
Gabriele Di Luozzo, MD, Aditya S. Shirali, BS, Robin Varghese, MD, Hung-Mo Lin, ScD,
} Aaron J. Weiss, MD, Moritz S. Bischoff, MD, and Randall B. Griepp, MD

\begin{abstract}
Objective: We assessed quality of life and survival in elderly patients after complex aortic operations to aid in surgical decision making.

Methods: A retrospective review was performed of 93 patients who underwent descending thoracic aneurysm or thoracoabdominal aortic aneurysm (TAAA) repair from 2002 to 2008. A Cox model was used for survival analysis. The SF-36 Item Health Survey was administered to assess postoperative quality of life in 39 patients and was compared with age- and gender-matched normal scores.

Results: The mean age at operation was $75 \pm 4.1$ years; $51 \%$ of patients were male. In-hospital mortality was $15 \%$. One-year survival was $69 \%$, and 5 -year survival was $45 \%$. Only acute respiratory distress syndrome was a predictor of in-hospital mortality (hazard ratio $=3.75 ; P<.01$ ) and 1 -year mortality (hazard ratio $=4.61$; $P<.001)$. After 1 year, patients enjoyed longevity equivalent to that of a normal age- and gender-matched population (standardized mortality ratio $=1.06 ; P=.81$ ). Being male is a predictor of long-term survival (hazard ratio $=0.18 ; P<.05$ ). For women, extremely low and high body mass indexes (quadratic term $=0.020 ; P<.05$ ) with an inflection point of body mass index of 28 is a risk factor of long-term survival. Quality of life scores were similar to those of the general population except for lower vitality scores, (s-score $=-0.67,95 \% \mathrm{CI},-1.09$ to $-0.26)$.
\end{abstract}

Conclusions: TAAA repair in this selected older surgical population yields acceptable survival beyond the first year. Among 1-year survivors, quality of life is similar to that of an age- and gender-matched population.

(J Thorac Cardiovasc Surg 2013;145:378-84)

The increasing life expectancy of the United States population has led to a larger number of septuagenarians and octogenarians requiring cardiac surgery, particularly complex aortic procedures. ${ }^{1,2}$ Improvements in surgical and extracorporeal perfusion techniques and perioperative management have dramatically reduced the number of complications of cardiac surgical procedures among elderly patients. ${ }^{3}$ Retrospective studies over the past decade have shown that elderly patients undergoing cardiac procedures have an acceptable long-term survival and significant improvement in functional status. ${ }^{4}$

With improvements in the diagnosis of descending thoracic (DTA) and thoracoabdominal aortic aneurysms (TAAA), surgical repair rates have increased and have led to decreased mortality over the past 20 years. ${ }^{5}$ In addition, postoperative complications of DTA and TAAA—such as respiratory failure, stroke, and paraplegia — have also been

From the Department of Cardiothoracic Surgery, Mount Sinai School of Medicine, New York, NY.

Disclosures: Authors have nothing to disclose with regard to commercial support. Received for publication April 24, 2011; revisions received Dec 14, 2011; accepted for publication Jan 24, 2012; available ahead of print Feb 27, 2012.

Address for reprints: Gabriele Di Luozzo, MD, Assistant Professor, Department of Cardiothoracic Surgery, Mount Sinai School of Medicine, 1190 Fifth Ave, PO Box 1028, New York, NY 10029 (E-mail: gabriele.diluozzo@mountsinai.org). $0022-5223 / \$ 36.00$

Copyright (c) 2013 by The American Association for Thoracic Surgery doi:10.1016/j.jtcvs.2012.01.068 reduced almost in half. ${ }^{4,6}$ Nevertheless, physicians are still reluctant to recommend such invasive procedures to septuagenarians and octogenarians because of the high postoperative risk and the assumption that quality of life (QoL) will be diminished. ${ }^{7-9}$ Very few studies have actually assessed these outcomes in elderly patients after open repair.

The purpose of this study was to evaluate long-term survival, QoL, and risk factors for mortality among a selected group of septuagenarians and octogenarians after open DTA and TAAA repair. Although thoracic endovascular aortic repair (TEVAR) is an attractive option for patients in their seventh and eighth decades of life, some patients will not be suitable for endovascular techniques. We examine the subset of patients referred for open surgery.

\section{METHODS}

\section{Patient Demographics}

A review of our institutional database disclosed 93 septuagenarian and octogenarian patients who underwent surgical repair of DTA or TAAA from October 2002 to October 2008. The institutional review board approved this retrospective research and waived the need for individual patient consent.

Table 1 summarizes demographics and preoperative clinical and operative characteristics of the patient cohort. The data were obtained from our thoracic aortic aneurysm database. Fifty-two (55.9\%) patients had undergone previous cardioaortic procedures. Most of the patients undergoing reoperation had had 1 previous aortic operation, but 14 had had 2 and 1 had undergone 3 previous aortic procedures. 


\section{Abbreviations and Acronyms \\ ARDS = acute respiratory distress syndrome \\ $\mathrm{CI}=$ confidence interval \\ COPD $=$ chronic obstructive pulmonary disease \\ DTA $=$ descending thoracic aortic aneurysm \\ $\mathrm{OR}=$ odds ratio \\ QoL = quality of life \\ SF-36 = Medical Outcomes Study Short Form 36 \\ SMR = standardized mortality ratio \\ TAAA $=$ thoracoabdominal aortic aneurysm \\ TEVAR $=$ thoracic endovascular aortic repair}

\section{Surgical Management}

Replacement was limited to the descending thoracic aorta in $22(23.7 \%)$ patients and extended to the thoracoabdominal aorta in $71(76.3 \%)$ patients. Our surgical technique has previously been described in detail. ${ }^{10}$ The decision to use hypothermic circulatory arrest was prompted by technical considerations, often involving the feasibility and safety of clamping the aorta proximal to the repair.

In brief, somatosensory evoked potentials were elicited by stimulation of the posterior tibial nerves and recordings were made from the scalp overlying the somatosensory cortex. For motor evoked potential monitoring, the stimuli applied to the motor cortexes were recorded from the skin over the tibialis anterior and abductor pollicis muscles. A decrease greater than $50 \%$ in amplitude with concomitant increased delay was considered to reflect a spinal cord ischemic event. Somatosensory evoked potential and motor evoked potential monitoring was performed in 74 $(80 \%)$ patients.

The cerebrospinal fluid pressure was monitored during the operation and postoperatively: the cerebrospinal fluid was drained at a maximum rate of 15 to $20 \mathrm{~mL} / \mathrm{h}$ so long as the pressure remained above $10 \mathrm{~mm} \mathrm{Hg}$.

\section{Follow-up}

Patients were followed up by the referring cardiologist and cardiothoracic surgeon and were contacted periodically by our research personnel. Annual computed tomographic scans were performed in the majority of patients as part of our monitoring program. Postoperative events were compiled and analyzed according to the Guidelines for Reporting Morbidity and Mortality after Cardiac Valvular Operations and our institutional checklist. For this study, the follow-up was closed on November 31, 2009 , and was $100 \%$ complete. Long-term survival was evaluated for the 64 patients still alive 1 year postoperatively (average, $3.8 \pm 1.6$ years; median follow-up, 3.8 years; range, 1.0-7.1 years). Patients were determined to be alive by consulting the Social Security Death Index or by telephone interview with the patient, next of kin, or primary care physician.

\section{QoL Assay}

The Medical Outcomes Study Short Form 36 (SF-36) Health Survey, version 2, was used to assess QoL for all patients who survived the first year postoperatively. ${ }^{11}$ The SF-36 is a generic instrument measuring health-related QoL. It comprises 8 categories: physical functioning, role limitations because of physical health, role limitations because of emotional health, mental health, social functioning, bodily pain, vitality, and general health. The questionnaire was administered in its entirety over a telephone interview for 39 of 48 patients who were still alive in November 2009. The results of the survey were compared with the normative scores of the age- and gender-matched populations.

\section{Statistical Analysis}

Data were entered in an Excel spreadsheet (Microsoft Corp, Redmond, Wash) and transferred to an SAS file (SAS Institute, Inc, Cary, NC) for data description and analysis. Patient and disease characteristics are described as percents, median (range), or means (standard deviation). Univariate analysis was performed first, followed by stepwise multivariate analysis. The initial list of covariates included all variables having a $P$ value $<.2$ in the univariate analysis. Because all censored patients had at least 1 year of follow-up time, logistic regression was implemented to determine risk factors for respective in-hospital and 1-year mortality. Effects were expressed in terms of odds ratios (ORs) with $95 \%$ confidence intervals (CIs).

For long-term survival, conditional on 1-year survival after surgical intervention, Cox regression was used and effects were expressed in terms of hazard ratios with $95 \%$ CIs. To test whether the proportional hazards assumption was valid, we created an interaction term between the risk factor and the log of the survival time and included it in the Cox model. If the time-dependent covariate was significant or the Kaplan-Meier curves crossed between groups for the covariate, then the assumption might be violated.

All of the preoperative and postoperative risk factors listed in Tables 1 and 2 were not significant (all $P>.15$ ), except gender $(P=.07)$. Inasmuch as there were only 2 deaths in men, gender-stratified analysis was performed. Smoothed lines (using the splines method) of the martingale residuals against the covariates were used to determine the proper functional forms for age and body mass index.

Long-term survival probabilities were estimated from a Kaplan-Meier life table. We also estimated the annual death rate per person-year of follow-up, as well as the standardized mortality ratio (SMR). This gives the observed numbers of deaths relative to the number that would be expected based on New York State population death rates for comparable ages, genders, and follow-up times. Statistical significance of the SMR was tested under a Poisson model.

All statistical analysis was carried out using SAS (SAS Institute, Inc), and the level of statistical significance for hypothesis testing and entry and stay criteria for stepwise regression was set to be .05 .

\section{RESULTS}

\section{Preoperative Patient Characteristics}

The preoperative demographic data are detailed in Table 1. There were 47 men and 46 women. The median age was 75 years (70-86 years). Forty-four percent of the patients had a history of smoking and $23 \%$ were active smokers. One-fifth had a diagnosis of chronic obstructive pulmonary disease (COPD). Twenty-two of the 93 patients had an isolated DTA and 31\% (29/93) had a type I TAAA. Ten patients had a type II TAAA.

\section{Intraoperative Characteristics}

Table 1 summarizes the intraoperative characteristics observed in these patients. The table details the urgency of operation, conduct of the operation, perfusion techniques, and transfusion requirements.

\section{Postoperative Complications}

The in-hospital mortality was $13.6 \%$ for isolated DTA and $15.5 \%$ for TAAA, with an overall mortality of $15.1 \%$. The in-hospital mortality for emergency operations was $11.1 \%$. The in-hospital mortality was $16 \%$ for the septuagenarians and $11 \%$ for the octogenarians. The median 
TABLE 1. Demographics and preoperative clinical and operative characteristics

\begin{tabular}{|c|c|}
\hline Variables & No. $(\%)(n=93)$ \\
\hline \multicolumn{2}{|l|}{ Gender } \\
\hline Male & $47(51 \%)$ \\
\hline Female & $46(49 \%)$ \\
\hline Age $($ mean $\pm S D), y$ & $75.4 \pm 4.1$ \\
\hline Age (median), y & $75(70-86)$ \\
\hline \multicolumn{2}{|l|}{ Risk factors } \\
\hline COPD & $21(22.6 \%)$ \\
\hline History of smoking & $41(44.0 \%)$ \\
\hline Active smoker & $21(22.6 \%)$ \\
\hline CAD & $31(33.0 \%)$ \\
\hline Previous CABG & $17(18.3 \%)$ \\
\hline Previous stent & $5(5.4 \%)$ \\
\hline History of stroke/TIA & $12(12.9 \%)$ \\
\hline Hypertension & $78(83.9 \%)$ \\
\hline IDDM & $12(12.9 \%)$ \\
\hline Dialysis & $4(4.3 \%)$ \\
\hline \multicolumn{2}{|l|}{ Timing of operation } \\
\hline Elective & $66(71 \%)$ \\
\hline Rupture & $16(17.2 \%)$ \\
\hline Emergency/urgent & $11(12 \%)$ \\
\hline Reoperation & $25(26.8 \%)$ \\
\hline \multicolumn{2}{|l|}{ Etiology of aneurysm } \\
\hline Degenerative & $36(39 \%)$ \\
\hline Acute dissection & $5(5.3 \%)$ \\
\hline Chronic dissection & $12(13 \%)$ \\
\hline Atherosclerotic & $40(43 \%)$ \\
\hline \multicolumn{2}{|l|}{ Operative data } \\
\hline CSF catheter & $55(59.1 \%)$ \\
\hline $\mathrm{HCA}$ & $18(19.3 \%)$ \\
\hline Femoral-femoral (partial bypass) & $45(48.3 \%)$ \\
\hline Femoral-atrial (left heart bypass) & $30(32.2 \%)$ \\
\hline Aortic crossclamp time (mean $\pm \mathrm{SD})$, min & $56.5 \pm 9.8$ \\
\hline $\mathrm{CPB}$ time (mean $\pm \mathrm{SD})$, min & $83.3 \pm 77$ \\
\hline HCA time (mean $\pm \mathrm{SD})$, min & $31.9 \pm 7.6$ \\
\hline
\end{tabular}

$S D$, Standard deviation; $C O P D$, chronic obstructive pulmonary disease; $C A D$, coronary artery disease; $C A B G$, coronary artery bypass grafting; $T I A$, transient ischemic attack; IDDM, insulin-dependent diabetes mellitus; $C S F$, cerebrospinal fluid; $H C A$, hypothermic circulatory arrest; $C P B$, cardiopulmonary bypass.

hospital stay was 15.5 days (range 6-102 days). Three $(3.2 \%)$ patients had paraplegia and $6(6.5 \%)$ patients had strokes postoperatively, confirmed by either computed tomographic or magnetic resonance imaging studies (Table 2).

\section{Predictors of In-Hospital and 1-Year Mortality}

Univariate analysis identified postoperative pneumonia (OR, 4.64; 95\% CI, 1.35-15.95; $P<.01$ ), tracheostomy (OR, $4.27 ; 95 \%$ CI, 1.30-14.01; $P=.01$ ), and acute respiratory distress syndrome (ARDS) (OR, 5.71; 95\% CI, 1.5021.84; $P<.01)$ as significant risk factors for in-hospital mortality. Postoperative acute renal failure, arrhythmia, paraplegia, stroke, and the preoperative factors listed in Table 1 (except gender) did not significantly increase the risk for in-hospital death.
TABLE 2. Summary of postoperative details and complications of the entire cohort $(\mathbf{n}=93)$

\begin{tabular}{lc}
\hline \multicolumn{1}{c}{ Variables } & No. $(\%)$ (n= 93) \\
\hline In-hospital mortality & $14(15.1 \%)$ \\
Paraplegia & $3(3.2 \%)$ \\
Stroke & $6(6.5 \%)$ \\
Renal insufficiency & \\
$\quad$ Temporary dialysis & $4(4.3 \%)$ \\
Permanent dialysis & $8(8.6 \%)$ \\
ARF & $13(13.9 \%)$ \\
Respiratory complications & \\
Tracheostomy & $22(23.7 \%)$ \\
Reintubation & $16(17.2 \%)$ \\
Respiratory failure & $32(34.4 \%)$ \\
ARDS & $12(12.9 \%)$ \\
Cardiac complications & \\
MI & $1(1.1 \%)$ \\
Arrhythmia & $26(28.0 \%)$ \\
Hospital stay (d) & \\
Mean \pm SD & $24.6 \pm 28.0$ \\
Median (range) & $15.5(6-102)$ \\
\hline$A R F$, Acute renal failure; $A R D S$, acute respiratory distress syndrome; $M I$, myocardial \\
infarction; $S D$, standard deviation.
\end{tabular}

Analysis of 1-year mortality identified tracheostomy (OR, 6.53; 95\% CI, 2.31-18.45; $P<.01$ ), respiratory failure (OR, 4.63; 95\% CI, 1.81-11.83; $P<.01$ ), and ARDS (OR, 9.15; 95\% CI, 2.25-37.14; $P<.01)$ as being significant postoperative risk factors. No other risk factors were identified.

Only ARDS was identified by multivariate analysis as being an independent risk factor for both in-hospital and 1 -year mortality. ARDS developed in $12(12.9 \%)$ of the 93 patients, comprising $36 \%$ of in-hospital deaths and $31 \%$ of 1 -year mortality. There was a strong correlation between ARDS and the other postoperative complications identified in the univariate analysis. Specifically, 11 of the 12 patients with ARDS had postoperative acute respiratory failure and required tracheostomy; 6 had pneumonia.

\section{Long-Term Survival}

Long-term survival was evaluated for the 64 patients alive after the first year. For patients alive after 1 year, the adjusted 3-, 5-, and 7-year survivals were $88 \%, 76 \%$, and $62 \%$, respectively (Figure 1). The SMR of our cohort in comparison with a New York State age-gender matched population, starting 1 year postoperatively, was 1.06 (95\% CI, 0.65-1.74, $P=.81$ ). Our patients had subsequent longevity similar to that of a matched New York State population if they survived the first postoperative year. The unadjusted 3-, 5-, and 7- year survivals were $60.7 \%, 45.3 \%$, and $42.7 \%$, respectively.

To correct for the confounding effect of gender, we calculated standardized mortality for both genders compared with an age- and gender-matched New York State 


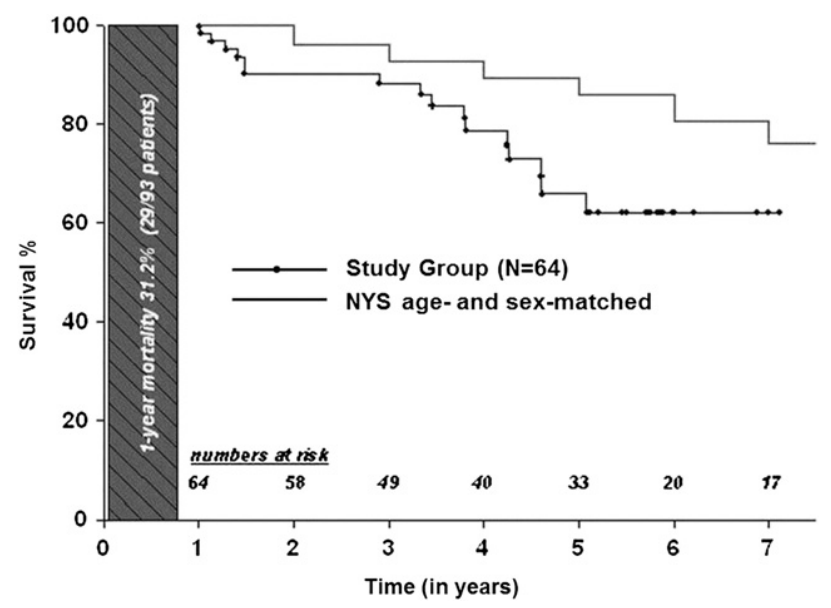

FIGURE 1. Survival curve of deaths for 64 patients alive 1 year after surgical repair compared with the New York State (NYS) age- and sex-matched population.

population (Figure 2, $A$ and $B$ ). The SMR for women was $1.98(95 \% \mathrm{CI}, 1.17-3.34, P=.01)$ and $0.25(95 \% \mathrm{CI}$, $0.06-1.00 ; P=.05)$ for men, compared with a matched New York State population: the female patients were twice as likely to die as a comparable population (Figure 2, A). The men had better long-term survival than the age- and gender-matched population (Figure 2,B). The linearized death rate of the entire group was $5.6 \%$ per patient-year, but the linearized death rate for women was $8.6 \%$ per patient-year, and only $1.6 \%$ per patient-year in men.

In the univariate analysis using data from the 64 one-year survivors, gender was highly significant. Among the 16 deaths, only 2 occurred in men (the hazard ratio for men was 0.16 ; $95 \% \mathrm{CI}, 0.04-0.72 ; P=.02$ ). Because the proportional hazards assumption was also questionable for gender, gender-stratified analysis was subsequently performed. In women, the only significant risk factor was body mass index. In the Cox model, the beta-coefficient for the linear term is -1.135 (standard error $=.454 ; P=.01$ ) and for the quadratic term is .020 (standard error $=.008 ; P=.01$ ), with an inflection point of the risk pattern around body mass index of 28 . Thus high mortality is associated with extremely low and high body mass indexes in women. No long-term risk factors were identified for men.

\section{QoL}

At the time of follow-up in November 2009, 48 survivors were identified. Among the survivors, 43 patients were living in their homes or with family members, 4 were living outside the United States, and only 1 patient was in a nursing home. Of the survivors, $81 \%$ provided responses to the SF$36 \mathrm{QoL}$ surveys, 4 patients were traveling or living outside the United States, and 5 patients were unreachable. All of the 39 survey responders had undergone their complex aortic procedure at least 1 year earlier, with a median follow-up
Study Group vs NY State - Females

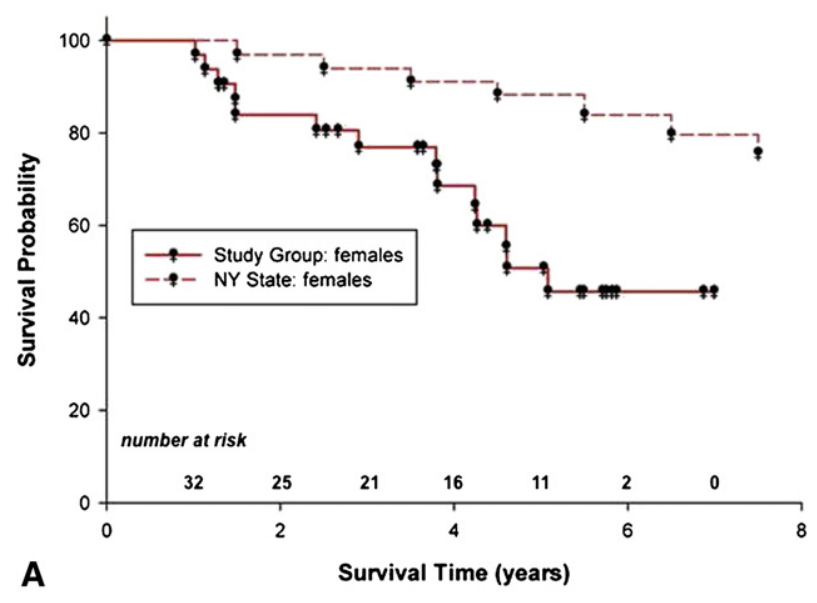

Study Group vs NY State - Males

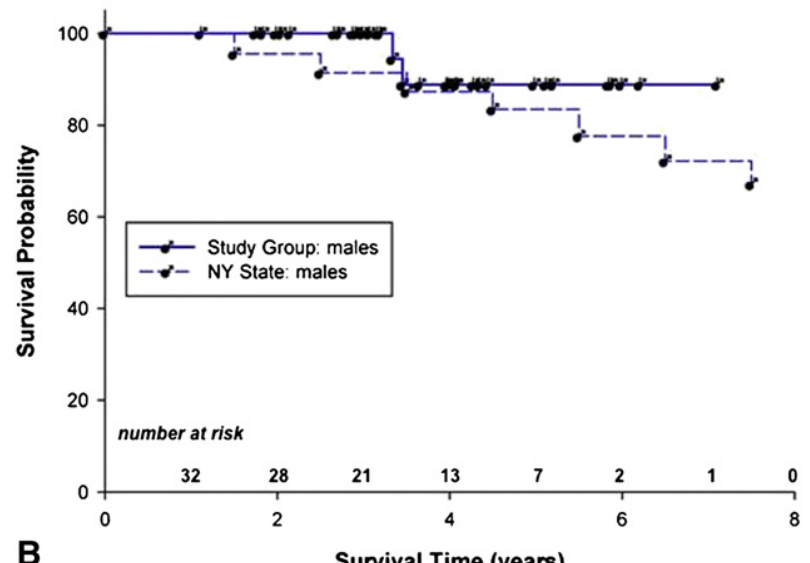

FIGURE 2. Survival curve for deaths of 32 female patients (A) and 32 male patients (B) alive 1 year after surgical repair compared to a genderspecific New York (NY) State age-matched populations.

time of 4.1 years (range, 1.1-7.1 years) and an average age of $75.6 \pm 4.2$ years. No difference in follow-up time and age was found between responders and nonresponders $(n=25)$, which includes patients who died or who were unreachable. Therefore, we believe that the survey responders are representative of the long-term survivors in our study.

Figure 3 demonstrates the differences in QoL scores between the respondents and age- and gender-matched data from the general US population older than 70 years. Across all QoL domains, respondents scored slightly lower than the matched US population. However, these slight differences were not statistically significant except in the vitality domain (s-score $=-0.67 ; 95 \% \mathrm{CI}=-1.09$ to -0.26 ).

\section{DISCUSSION}

The outlook for a patient with a large DTA or TAAA treated conservatively is dismal. Most patients will die 


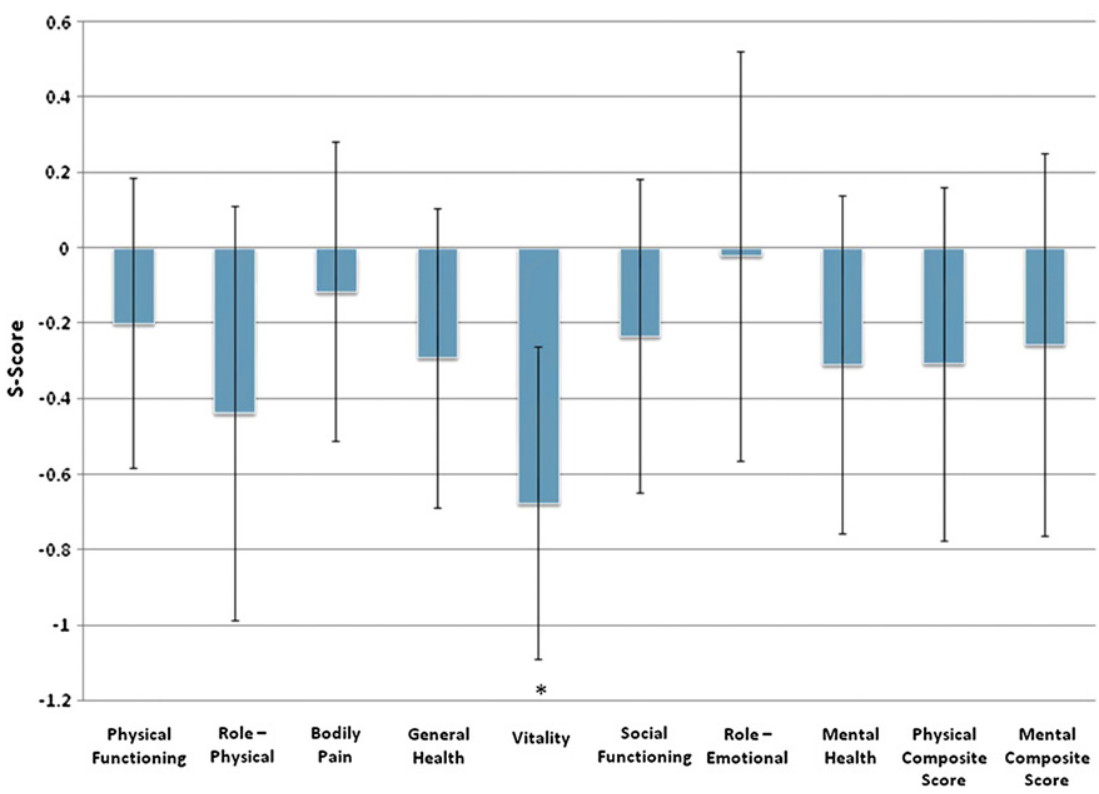

FIGURE 3. Standardized differences in quality of life scores ( $s$-scores) between the patient group $(\mathrm{n}=39)$ and the age- and gender-matched populations' normative scores. The vitality s-score $\left(^{*}\right)$ is statistically significant.

within 5 years of diagnosis from rupture, dissection, or another aorta-related complication. ${ }^{6,12}$ In a patient with a thoracic aneurysm with a diameter equal to or greater than $6 \mathrm{~cm}$, the composite annual risk of rupture, dissection, or death is $15.6 \% .{ }^{13}$ However, patients with atherosclerotic and degenerative thoracic aneurysms are commonly afflicted with multiple life-limiting medical conditions. This is the clinical quandary: patients with thoracic aneurysms who meet criteria for aortic reconstruction are often not robust enough to undergo surgery. The growing population of septuagenarians and octogenarians will continue to challenge the clinician with this dilemma as national registries document the increasing prevalence of thoracic aortic disease. ${ }^{14}$

The risk of intervention in elderly patients and its impact on the QoL must be weighed against the potential benefit, particularly when cardioaortic operations are being considered. The physiologic insult of open repair of DTA and TAAA is often poorly tolerated in the elderly population: major adverse events occur in up to $26 \%$ of patients. ${ }^{15}$ However, we observed only an $11 \%$ in-hospital mortality in the octogenarians undergoing open surgery and $13.6 \%$ mortality with isolated DTA. Fehrenbacher and associates ${ }^{15}$ have reported a $1.3 \%$ mortality for elective isolated DTA and type I TAAA using DHCA, a favorable result not matched by TEVAR. ${ }^{15}$ The 1 subset of patients who may benefit from TEVAR are elderly patients with a ruptured thoracic aortic aneurysm. In our study, there were 16 patients with rupture who were treated with open surgery. The in-hospital mortality was $11.1 \%$, which is not significantly lower than the overall in-hospital mortality of $15.1 \%$. The majority of the operations in this group were isolated DTA resections, which are usually of lower surgical complexity. In this small cohort of patients, there were few postoperative complications such as paraplegia (0 patients), stroke (1 patient), and renal failure (1 patient), none of which were independent risk factors for in-hospital mortality. Although $25 \%$ of emergency patients required a tracheostomy-a definite risk factor for in-hospital mortality - the in-hospital mortality of the emergency patients was nevertheless low.

Numerous studies have attempted to show the benefit of endografting for thoracic aneurysms, especially in elderly patients. A recent study by Preventza and associates ${ }^{16}$ examined the role of TEVAR in octogenarians and reported an overall in-hospital mortality of $10 \%$, suggesting elective TEVAR is a safe option for DTA. The results of TEVAR in a large series of patients with TAAA with fenestrated grafts or extra-anatomic bypass remains to be seen. With similar mortality rates when comparing TEVAR and open isolated DTA repair in octogenarians, the potential benefits of the endovascular approach must be weighed against the risk of endoleak and possible subsequent need for reintervention. Nonetheless, TEVAR for the frail, elderly patient is an attractive option. Whether or not to undertake any treatment at all must be balanced against the anticipated risk of rupture or death in patients treated conservatively, which can be as high as $36 \%$ in 1 year, and $48 \%$ in $2 .{ }^{17}$ The results of this study suggest that some high-risk septuagenarians and octogenarians should be offered surgery, albeit cautiously.

As the perioperative care of patients improves and inhospital mortality declines, it is clear that more patients will survive DTA and TAAA operations in the short term. However, it may be a pyrrhic victory to subject an elderly 
patient to such an extensive operation if he or she is likely to die before 1 year postoperatively. We believe strongly that the success of open surgery should not be judged by discharge home or to a nursing facility, especially in septuagenarians and octogenarians. The majority of these patients have many medical illnesses that can be exacerbated by postoperative complications with sequelae whose impact is felt for several months and which influence 1-year survival. In this study, the 1 -year survival was only $69 \%$. Inasmuch as we gauged the success of the operation on the basis of 1-year survival, we thought it was appropriate to consider long-term survival as starting from 1 year postoperatively. The patients in our study who survived the first year, however, had a long-term survival similar to an age- and gendermatched New York State population. Similar conclusions could be extrapolated for TEVAR based on Medicare data, which found similar 5-year survival between patients treated with open procedures and those subjected to TEVAR. ${ }^{18}$

The majority of deaths in the first year were related to pulmonary dysfunction. Patients with TAAA are at high risk for pulmonary dysfunction after surgery because of the high prevalence of cardiovascular disease, COPD, and protracted smoking history. ${ }^{19}$ Pulmonary complications developed in $23 \%$ of the patients who were active smokers at the time of surgery; in those with a significant smoking history and/or COPD, the pulmonary complication rate was $39 \%$ and $43 \%$, respectively. Patients with significant pulmonary disease but with favorable anatomic characteristics may be better served with TEVAR to avoid thoracotomy and division of the diaphragm. Patients with severe pulmonary dysfunction who are not candidates for TEVAR should be considered for conservative management unless rupture is imminent or its risk is very high, inasmuch as in our cohort of patients the 1 -year mortality was $31 \%$ and the leading cause of death was pulmonary.

$\mathrm{We}^{20}$ previously reported the unexpected finding of poorer long-term survival in women undergoing proximal aortic reconstruction, In this study, although the SMR of men was significantly better than that of a comparable New York State population, women were nearly twice as likely to die during follow-up as their matched normal counterparts. We were unable to ascertain the cause of death in most patients of either gender during follow-up. In our cohort of patients who survived 1 year, however, 71.4\% of those with a preoperative history of COPD were female. Although the higher prevalence of COPD among women may explain their poorer outcome (inasmuch as inhospital and 1-year mortality were dependent on postoperative pulmonary complications), COPD was not found on the Cox regression to be an independent predictor for gender-based differences in long-term survival $(P>.20)$. In this study, having a body mass index less than 23 was a significant risk factor for long-term survival for women only. Several studies have found a strong association between low body mass index and increased postoperative pulmonary complications and mortality after cardiac surgery. ${ }^{21}$ Low body mass index $\left(<25 \mathrm{~kg} / \mathrm{m}^{2}\right)$ has been associated with COPD and as an independent risk factor for 1-year mortality in other studies. ${ }^{22}$ Low body mass index may therefore be a surrogate for COPD or severe pulmonary dysfunction among our female patients with DTA and TAAA.

The patients who survived the first year after surgery enjoyed a good QoL compared with a matched New York State population. There are few other studies that have examined QoL after DTA and TAAA repair in elderly patients. ${ }^{23,24}$ In a study of octogenarians undergoing cardiac surgery, the majority were discharged home, where they functioned independently. The absence of a significantly lower score in most domains on the SF-36 survey in our patients compared with an age- and gender-matched population underscores the idea that our exclusion criteria for open thoracic aortic surgery should not include age.

In our patients, the vitality domain score in the SF-36 survey was significantly lower than in the matched population. Other studies have not shown a difference in this domain. Interestingly, patients treated with TEVAR and open surgical repair had a similar QoL ${ }^{25}$ Our study population represents a select group of patients who were suitable for open surgical repair on the basis of established selection criteria. Inherent in this patient assessment is a potential selection bias for elderly patients who will tolerate the physiologic insult of an open operation. The small number of patients who received QoL assessments is a limitation of the study, and we acknowledge that this study as a whole represents a very select group of elderly patients who were offered open repair and survived 1 year postoperatively. The information presented in this article is from a small group of patients who were treated at a high-volume aortic center. This may not represent "real world" results in this elderly population: the specialized, multidisciplinary team assembled to do such a high volume of cases may have a significant impact on outcomes. Nevertheless, characterization of the long-term survival predictors and QoL of this select group is informative for those patients who survive 1 postoperative year.

In brief, septuagenarians and octogenarians can undergo open repair after risk stratification and calculation of annual risk of aortic rupture. In this subset of patients, open surgical repair performed at a high-volume center currently has an in-hospital mortality comparable with that of patients undergoing TEVAR for isolated DTA, and probably better than that of patients undergoing hybrid TAAA repairs. With time, as TEVAR technology improves, we anticipate that an increasing number of elderly patients will be managed with an endovascular approach. However, at present, this report documents that elderly patients who survive open aortic surgery can lead productive and independent lives. 


\section{References}

1. Alexander KP, Anstrom KJ, Muhlbaier LH, Grosswald RD, Smith PK, Jones RH, et al. Outcomes of cardiac surgery in patients $>$ or $=80$ years: results from the National Cardiovascular Network. J Am Coll Cardiol. 2000;35:731-8.

2. Craver JM, Puskas JD, Weintraub WW, Shen Y, Guyton RA, Gott JP, et al. 601 octogenarians undergoing cardiac surgery: outcome and comparison with younger age groups. Ann Thorac Surg. 1999;67:1104-10.

3. Mittermair RP, Muller LC. Quality of life after cardiac surgery in the elderly. $J$ Cardiovasc Surg (Torino). 2002;43:43-7.

4. Conrad MF, Crawford RS, Davison JK, Cambria RP. Thoracoabdominal aneurysm repair: a 20-year perspective. Ann Thorac Surg. 2007;83:S856-61; discussion S890-2.

5. Schermerhorn ML, Giles KA, Hamdan AD, Dalhberg SE, Hagberg R, Pomposelli F. Population-based outcomes of open descending thoracic aortic aneurysm repair. J Vasc Surg. 2008;48:821-7.

6. Schepens MA, Kelder JC, Morshuis WJ, Heijmen RH, van Dongen EP, ter Beek HT. Long-term follow-up after thoracoabdominal aortic aneurysm repair. Ann Thorac Surg. 2007;83:S851-5; discussion S890-2.

7. Estrera AL, Miller CC, Chen EP, Meada R, Torres RH, Porat EE, et al. Descending thoracic aortic aneurysm repair: 12-year experience using distal aortic perfusion and cerebrospinal fluid drainage. Ann Thorac Surg. 2005;801290-6; discussion 1296

8. Etz CD, Halstead JC, Spielvogel D, Shahani R, Lazala R, Homann TM, et al. Thoracic and thoracoabdominal aneurysm repair: is reimplantation of spinal cord arteries a waste of time? Ann Thorac Surg. 2006;82:1670-7.

9. Ware JE, Kosinski M, Bjorner JB, Turner-Bowker DM, Gandek B, Maruish ME User's manual for the SF-36v2 Health Survey. 2nd ed. Lincoln (RI): QualityMetric Incorporated; 2007.

10. Bickerstaff LK, Pairolero RC, Hollier LH, Melton LJ, Van Peenen HJ, Cherry KJ, et al. Thoracic aortic aneurysms: a population-based study. Surgery. 1982;92: 1103-8.

11. Davies RR, Goldstein LJ, Coady MA, Tittle SL, Rizzo JA, Kopf GS, et al. Yearly rupture or dissection rates for thoracic aortic aneurysms: simple prediction based on size. Ann Thorac Surg. 2002;73:17-27; discussion 27-8.

12. Day J. National population projections. U.S. Census Bureau 2001. Cited 2010; available from: http://www.census.gov/population/www/pop-profile/natproj.html.

13. Zoli S, Etz CD, Roder F, Mueller CS, Brenner RM, Bodian CA, et al. Long-term survival after open repair of chronic distal aortic dissection. Ann Thorac Surg. 2010;89:1458-66.
14. Hansen PA, Richards JM, Tambyraja AL, Khan LR, Chalmers RT. Natural history of thoraco-abdominal aneurysm in high-risk patients. Eur J Vasc Endovasc Surg. 2010;39:266-70.

15. Fehrenbacher JW, Hart JW, Huddleston E, Siderys H, Rice C. Optimal endorgan protection for thoracic and thoracoabdominal aortic aneurysm repair using deep hypothermic circulatory arrest. Ann Thorac Surg. 2007;83: 1041-6.

16. Preventza O, Bavaria J, Ramaiah V, Moser GW, Szeto W, Wheatley G, et al. Thoracic endografting is a viable option for the octogenarian. Ann Thorac Surg. 2010;90:78-82

17. Conrad MF, Ergul EA, Patel VI, Paruchuri V, Kwolek CJ, Cambria RP. Management of diseases of the descending thoracic aorta in the endovascular era: a Medicare population study. Ann Surg. 2010;252:603-10.

18. Etz CD, Di Luozzo G, Bello R, Luehr M, Khan MZ, Bodian CA, et al. Pulmonary complications after descending thoracic and thoracoabdominal aortic aneurysm repair: predictors, prevention, and treatment. Ann Thorac Surg. 2007;83:S870-6; discussion S890-2.

19. Etz CD, Homann TM, Rane N, Bodian CA, Di Luozzo G, Plestis KA, et al. Aortic root reconstruction with a bioprosthetic valved conduit: a consecutive series of 275 procedures. J Thorac Cardiovasc Surg. 2007;133:1455-63.

20. Reeves BC, Ascione R, Chamberlain MH, Angelini GD. Effect of body mass index on early outcomes in patients undergoing coronary artery bypass surgery. $J$ Am Coll Cardiol. 2003;42:668-76.

21. Al-Sarraf N, Raza A, Rowley S, Hughes A, Tolan M, Young V, et al. Short-term and long-term outcome in low body mass index patients undergoing cardiac surgery. Gen Thorac Cardiovasc Surg. 2009;57:87-93.

22. Yang L, Zhou M, Smith M, Yang G, Peto R, Wang J, et al. Body mass index and chronic obstructive pulmonary disease-related mortality: a nationally representative prospective study of 220000 men in China. Int J Epidemiol. 2010;39: 1027-36.

23. Crawford RS, Pedraza JD, Chung TK, Corey M, Conrad MF, Cambria RP. Functional outcome after thoracoabdominal aneurysm repair. J Vasc Surg. 2008;48: 828-35.

24. Chaturvedi RK, Blaise M, Verdon J, Iqbal S, Ergina P, Cecere R, et al. Cardiac surgery in octogenarians: long-term survival, functional status, living arrangements, and leisure activities. Ann Thorac Surg. 2010;89:805-10.

25. Dick F, Hinder D, Immer FF, Hirzel C, Do DD, Carrel TP, et al. Outcome and quality of life after surgical and endovascular treatment of descending aortic lesions. Ann Thorac Surg. 2008;85:1605-12. 